\title{
Assessing the Relative Efficiency and Productivity Growth of the Taiwan LED Industry: DEA and Malmquist Indices Application
}

\author{
Chia Chi Sun \\ Grade Institute \& Department of International Business, Tamkang University, No. 151, Yingzhuan Road, \\ Danshui Town, New Taipei City 25137, Taiwan \\ Correspondence should be addressed to Chia Chi Sun; samsun0712@gmail.com
}

Received 20 January 2014; Revised 23 April 2014; Accepted 16 May 2014; Published 1 June 2014

Academic Editor: Shihua Li

Copyright (C) 2014 Chia Chi Sun. This is an open access article distributed under the Creative Commons Attribution License, which permits unrestricted use, distribution, and reproduction in any medium, provided the original work is properly cited.

With the rapid acceleration of global competition the need has arisen for a more systematic performance evaluation system. This research develops a two-stage performance evaluation system to help maximize performance evaluation success. The performance evaluation is an important approach for enterprises to give incentives and restraint to their operators. It is also an important channel for enterprise stakeholders to obtain performance information. This study analyzes the current evaluation system for the Taiwan LED industry. This research measures the performance of ten LED companies in Taiwan for the period 2003-2009. The proposed method is practical and useful. The evaluation model indicates that proposed method is more reasonable and easier to grasp than other methods. As a result, it is easier to popularize this evaluation method in enterprises. The proposed method presents a complete assessment model that helps managers identify items for improvement, while simultaneously promoting cost and time efficiencies in the LED industry.

\section{Introduction}

In todays fast moving rapidly changing business and technological environment, the performance evaluation system has become a crucial management tool. Tender determined using performance evaluation systems is widely used in high-tech industries. A remarkable phenomenon in the high-tech business over the last two decades has been the dramatic growth in the number and importance of performance evaluation systems. The performance evaluation is a necessary, beneficial process that provides annual feedback to a company about its' job effectiveness and efficiency. The performance evaluation and optimal weapon systems design are multiple criteria decision making problems [1]. In order to compete in todays competitive environment, many organizations have recognized benchmarking as being of strategic importance in the drive for better performance and commitment to achieving a competitive advantage [2]. Current performance evaluations have already become important means of investigating employee performance. Performance evaluations contribute to business' target attainment, business performance improvement, and improvement in employee behavior and promoting specific desired abilities. Over the past few decades performance analysis has received significant attention. Many studies have investigated performance evaluation methods [3-7]. Some literatures identified different key performance indicators, including tangible and intangible aspects [8-14]. It is essential for performance measurement application that a company's tangible and intangible targets are defined in a way that is more appropriate to the requirements and objects of these targets and that company strategy is more extensively operationalized, quantified, and linked in a mutually supportive way [15-18].

Accurate business performance evaluation is a key to success for enterprises. The performance evaluation and optimal weapon systems design are multiple criteria decision making problems [19]. In order to compete in today's competitive environment, many organizations have recognized benchmarking as being of strategic importance in the drive for better performance and commitment to achieving a competitive advantage $[20,21]$. The problem of performance evaluation complexity makes the development and application of standard models more difficult, while at the same time actually presenting motivation for the development of new, 
more flexible models, which, again, can be adapted to the specific interests of those who compare the alternatives.

In this paper we apply a new approach based on frontier production function to research the productivity growth of LED companies performance in Taiwan. The research framework is that of data envelopment analysis (DEA). DEA is a nonparametric method in operations research and economics for the estimation of production frontiers [22]. It is used to empirically measure productive efficiency of decision making units. There are also parametric approaches that are used for production frontiers estimation [23].

Under such a competitive environment, port performance measurement not only is a powerful management tool for port operators, but also constitutes a most important input for informing regional and national port planning and operations. Kumbhakar and Lovell [24] stated that crosssectional data provide a snapshot of producers and their efficiency and panel data provide more reliable evidence on their performance because they enable us to track the performance of each producer through a sequence of time periods. In order to overcome the potential problem associated with an analysis based on cross-sectional data, DEA window analysis is used in this paper for the first time and applied to the port industry to deduce efficiency trends. This paper continues by conducting the Malmquist productivity index (MPI) to estimate technological changes [25]. MPI is defined using nonparametric distance functions, which determine how far a firm is from its optimal production given the observed output and applied input. MPI can decompose the productivity growth into two mutually exclusive components: technical efficiency change and technical change overtime, which measures the change in efficiency frontier shift, respectively [26]. These are (i) technical efficiency change $(E)$; (ii) technological change $(P)$; (iii) pure technical efficiency change (PT); (iv) scale efficiency change $(S)$; and $(\mathrm{v})$ total factor productivity $(M)$ change [27].

The reminder of this paper is as follows. Section 2 presents the methodology, DEA, including the window analysis and Malmquist productivity indexes. Section 3 introduces the research design, which includes the research framework, research procedure, and variable measurement and sample selection. Section 4 presents the empirical results. Some managerial implications and ways of improving efficiency are discussed in Section 5.

\section{Data Envelopment Analysis (DEA) Model}

DEA is a mathematical linear programming approach based on the technical efficiency concept. It can be used to measure and analyze the TE of different entities: productive and nonproductive, public and private, and profit and nonprofit seeking firms [28]. The main advantages of DEA that make it suitable for measuring the efficiency of vehicle inspection agencies are as follows: (i) it allows the simultaneous analysis of multiple outputs and multiple inputs, (ii) it does not require an explicit a priori determination of a production function, (iii) efficiency is measured relative to the highest observed performance rather than against some average, and (iv) it does not require information on prices $[29,30]$. Since the LED companies in Taiwan are part of the public sector where economic behavior is uncertain and there is no price information on the services produced, the window analysis and Malmquist productivity index based on DEA approach is well suited for productivity measurement in this sector. It is a nonparametric approach that calculates efficiency level by performing linear programing for each unit in the sample [31]. DEA measures the efficiency of the decision-making unit by comparison with the best producer in the sample to derive compared efficiency $[31,32]$.

As we have seen DEA is based on the TE concept which is as follows [29-32]:

$$
\text { Technical efficiency }(\mathrm{TE})=\frac{\sum \text { weighted output }}{\sum \text { weighted input }} \text {. }
$$

Mathematically we can express the above relation using the following formula $[24,25]$ :

$$
E_{k}=\frac{\sum_{j=1}^{M} U_{j} O_{j k}}{\sum_{i=1}^{N} V_{i} I_{i k}}
$$

where $E_{k}$ is the TE for the $D M U_{k}$ (between 0 and 1), $k$ is the number of $D M U_{k}$ in the sample $(k=1, \ldots, K), N$ is the number of inputs used $(i=1, \ldots, N), M$ is the number of outputs $(j=1, \ldots, M), O_{j k}$ is the observed level of output $j$ from $D M U_{k}, I_{i k}$ is the observed level of input $i$ from $D M U_{k}$, $V_{i}$ is the weight of input $i$, and $U_{j}$ is the weight of output $j$.

To measure TE for $D M U_{k}$ using linear programing the following problem must be solved which is the following formula $[24,25,32]$ :

$$
\begin{array}{ll}
\operatorname{Max} & \mathrm{TE} \\
\text { s.t. } & E k \leq 1 \quad k=1,2, \ldots, K,
\end{array}
$$

where TE is either maximizing outputs from given inputs or minimizing inputs for a given level of outputs. The above problem cannot be solved as stated because of difficulties associated with nonlinear (fractional) mathematical programming. Charnes et al. [33] have developed a mathematical transformation which converts the above nonlinear programming to linear one.

Modified linear programming by the following formula [24, 25, 32, 33]:

$$
\begin{array}{ll}
\operatorname{Max} & \sum_{j=1}^{M} U_{j} O_{j k} \\
\text { s.t. } & \sum_{i=1}^{N} V_{i} I_{i k}=1 \\
& \sum_{j=1}^{M} U_{j} O_{j k} \leq \sum_{i=1}^{N} V_{i} I_{i k} \\
& U_{j}, V_{i} \geq \varepsilon>0 .
\end{array}
$$


2.1. Window Analysis. Based on the rule of thumb, the number $D M U_{k}$ should be greater than double of the sum of the inputs and outputs. In order to overcome the limited $D M U_{k}$ constraint the window analysis method proposed by Charnes et al. [33] is adopted in this study. Windows analysis is a time dependent version of DEA. In order to capture the variations in efficiency over time, Charnes et al. [33] proposed a technique called "window analysis" in DEA. Window analysis assesses the performance of a $D M U_{k}$ over time by treating it as a different entity in each time period. This method allows for tracking the performance of a process or unit $[33,34]$.

The basic idea is to regard each $D M U_{k}$ as if it were a different $D M U_{k}$ in each of the reporting dates. Each $D M U_{k}$ is then not necessarily compared with the whole data set, but instead only with alternative panel data subsets. The windows analysis is based on the assumption that what was feasible in the past remains feasible forever and that the treatment of time in windows analysis is more in the nature of averaging over the periods of time covered by the window [35]. DEA is initially used to analyze cross-sectional data where a given $D M U_{k}$ is compared with all other $D M U_{k}$ that produce during the same time period and where the role of time is ignored. However, this can be rather misleading because a dynamic context may give rise to seemingly excessive use of resources that are intended to produce beneficial results in future periods $[32,33]$. As such, panel data prevail over crosssectional data in that not only do they enable a $D M U_{k}$ to be compared with other counterparts, but also because the movement in efficiency of a particular $D M U_{k}$ can be tracked over a period of time. In so doing panel data are more likely to reflect the real efficiency of $D M U_{k}[32,33]$.

We briefly introduce the meaning of window analysis. Assume there are $N$ alternatives, $l=1, \ldots, N$, and each alternative has data for periods 1 to $M, m=1, \ldots, M$. The window length is fixed at $K$, the data from periods $1,2, \ldots, K$ will form the first row and the data from periods $2,3, \ldots, K, K+1$ will form the second row, and so on. One or more periods on the right will need to be shifted and a total of $M-K+1$ window rows exist. Each window is represented by $i=1, \ldots, M-K+1$, and the $i$ th window consists of the data in periods $j=i, \ldots, i+k-1$. There are $K$ sets of data to be evaluated. Therefore, there are a total of $N \times K D M U_{k}$ in that window $[32,33]$.

In order to apply window analysis DEA is used to evaluate the performance of all $D M U_{k}$ in the same window. The efficiency, $E_{i, j}^{l}$, of each $D M U$ will be entered in the right window position. The procedure will be repeated $M-K+1$ times to obtain all of the efficiency values in all windows. Window analysis uses all efficiency values of an alternative to generate some statistical values. The average efficiency $\left(M_{l}\right)$, variance among efficiencies of alternative $l\left(V_{l}\right)$, column range $\left(\mathrm{CR}_{l, m}\right)$, and the total range for alternative $l\left(\mathrm{TR}_{l}\right)[33$, 36] are included.

The average efficiency $\left(M_{l}\right)$ of alternative $l$ is obtained using the following formula $[32,33]$ :

$$
M_{l}=\frac{\sum_{t=1}^{M-k+1} \sum_{j=1}^{i+k-1} E_{i, j l}}{K \times(M-K+1)}, \quad l=1, \ldots, N .
$$

The variance among efficiencies of alternative $l, V_{l}$, is calculated using the following formula [32, 33]:

$$
V_{l}=\frac{\sum_{i}^{M-K+1} \sum_{j}^{i+k-1}\left(E_{i, j}^{l}-M_{l}\right)^{2}}{K \times(M-K+1)-1}, \quad l=1, \ldots, N .
$$

The variance in efficiency reflects the fluctuation in efficiency values for each alternative. If an alternative has higher average efficiency and small variance, its ranking can be higher compared to other alternatives.

Column range, $\mathrm{CR}_{l, m}$, can be used to compare the fluctuations in efficiencies among the alternatives. In each alternative, because the data for the first period $(m=1)$ and last period $(m=M)$ are being analyzed in only the first and the $M-K+1$ window, only one efficiency value is obtained for each of the two windows. The efficiencies in the first and last periods will not be included in the calculation of CR values. For the other periods the data for each alternative is used at least twice and at least two efficiency values are available for calculating the $\mathrm{CR}$ values $[30,31]$.

$\mathrm{CR}_{l, m}$ is the difference between the largest and the smallest efficiencies for alternative $l$ in period $m$ by the following formula $[33,37]$ :

$$
\begin{gathered}
\mathrm{CR}_{l, m}=\operatorname{Max}\left(E_{i, m}^{l}\right)-\operatorname{Min}\left(E_{i, m}^{l}\right), \\
i=\max (m-k+1,1), \ldots, \min (m, M-K+1), \\
m=1, \ldots, M .
\end{gathered}
$$

$\mathrm{CR}_{l, m}$ can be used to evaluate the stability of efficiency for an alternative in each period. $\mathrm{CR}_{l}$ is then the overall column range for alternative $l$, and it shows the greatest variation in efficiency for an alternative over different periods using the following formula $[33,37]$ :

$$
\mathrm{CR}_{l}=\operatorname{Max}_{m=2, \ldots, M-1}\left(\mathrm{CR}_{l, m}\right) \text {. }
$$

We can use a total range for evaluation in order to understand the stability of an alternative over different periods. The total range is the difference between the maximum and minimum efficiency values of alternatives in all windows.

The total range (TR) for alternative $l$ is the following formula $[33,37]$ :

$$
\begin{gathered}
\mathrm{TR}_{l}=\operatorname{Max}\left(E_{i, j}^{l}\right)-\operatorname{Min}\left(E_{i, j}^{l}\right), \\
i=1, \ldots, M-K+1 \\
j=i, \ldots, i+K-1 .
\end{gathered}
$$

DEA window analysis has been adapted in many academic fields such as industry analysis. Cullinane et al. [37] applied DEA windows analysis to container port production efficiency. Shahooth and Battall [38] used data envelopment analysis and window analysis in measuring and analyzing the relative cost efficiency of 24 Islamic banking institutions. Chang et al. [39] applied window analysis to analyze the dynamic efficiencies of Taiwan's TFT-LCD firms for the period from 2001 to 2005. 
2.2. Malmquist Productivity Indexes (MPI). The MPI were developed by Caves et al. based on the distance functions developed by Malmquist [40, 41]. Fare et al. [42] decomposed the productivity growth into two mutually exclusive components: technical efficiency change and technical change overtime, which measures the change in efficiency frontier shift, respectively [26]. The MPI expressed in DEA efficiency measures is defined as the ratio of the efficiency measures for the same production unit in two different time periods or between two different observations for the same period $[32,43]$. The study used the DEA approach outlined by Fare et al. [42] to construct the best-practice frontier for ten LED companies in Taiwan.

The MPI for any unit between period 0 and 1 with period $i$ frontier technology as a reference, $M_{i}(0,1)$, can be calculated using DEA measures obtained by solving the LP-problems [32], which is as follows:

$$
M_{i}(0,1)=\frac{E_{i 1}}{E_{i 0}}, \quad i=0,1 \in T .
$$

The $i$ is the frontier technology, $E_{i 0}$ is the input (output) efficiency measure for a unit observed in period 0 , and $E_{i 1}$ is input (output) efficiency for the same units observed in period 1 with technology $i$. The index, $M_{i}(0,1)$, shows the relative change in technical efficiency and $T$ represents the time period for the $D M U_{k}[32,44]$.

Malmquist productivity indexes are based on the nonparametric-parametric approach which can capture the productivity change in economic growth using a specific production function. The mathematics concept was borrowed from Odeck [32]. The denominator shows the proportional adjustment of the observed input vector of the unit in period 1 for observed outputs to be on the same frontier function $[45,46]$. The denominator is always between 0 and 1 , while the numerator can be greater than 1. It follows that when $M_{i}(0,1)>1$, then productivity has increased. If $M_{i}(0,1)<1$, then the productivity has decreased and if $M_{i}(0,1)=1$ the productivity is unchanged. This holds irrespective of the reference technology [32]. We can then transform the mathematics concept into a diagram, which is shown in Figure 1. The first year is $t_{0}$ and the second year is $t_{1}$. The model included one input variable $(x)$ and one output variable $(y)$. In the first year $t_{0}$, unit $K_{0}$ is observed with the combination $\left(y_{0}, x_{0}\right)$, the corresponding benchmark units on the frontier are $K_{1}\left(y_{0}, x_{00}\right)$ and $K_{2}\left(y_{0}, x_{10}\right)$. The efficiency measures $E_{00}$ and $E_{10}$ are equal to the ratios $\left(x_{00} / x_{0}\right)$ and $\left(x_{10}, x_{0}\right)$ [32]. Therefore, the MPI can be written as in (11). Equation (11) indicates that the MPI is the change in productivity between the two periods:

$$
M_{i}\left(t_{0}, t_{1}\right)=\frac{E_{i 1}}{E_{i 0}}=\frac{x_{i 1} / x_{1}}{x_{i 0} / x_{0}}=\frac{y_{1} / x_{1}}{y_{0} / x_{0}} .
$$

In relation to Figure 1 MPI can be decomposed into two parts. The first part is the technical efficiency change $(E)$

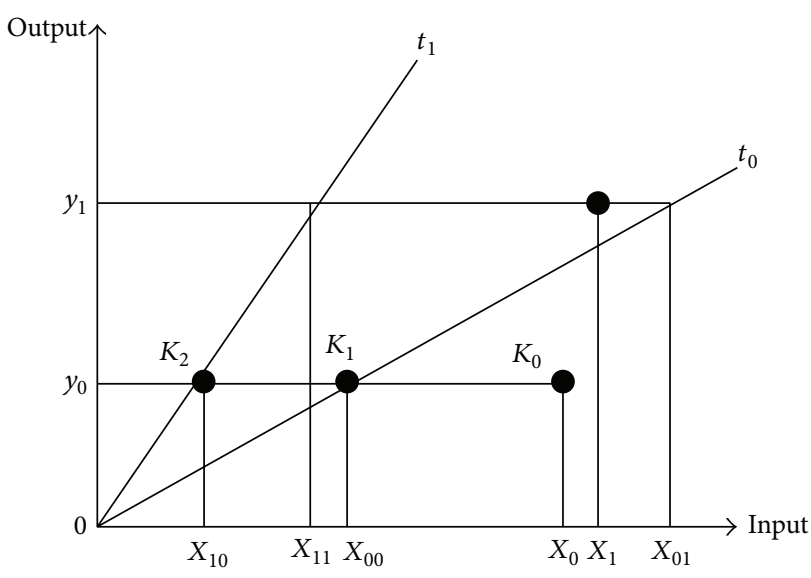

FIgURE 1: The MPI and its components. Source: Odeck [32].

and the second is the technological change $(P)$, represented by the following formula [32]:

$$
\begin{gathered}
M_{i}=E_{i} \times P_{i}, \quad i=0,1, \\
P_{i}\left(t_{0}, t_{1}\right)=\frac{E_{01}}{E_{11}}=\frac{x_{01} / x_{1}}{x_{11} / x_{1}}=\frac{x_{12}}{x_{22}}, \\
E_{i}\left(t_{0}, t_{1}\right)=\frac{E_{11}}{E_{00}}=\frac{x_{11} / x_{1}}{x_{00} / x_{0}}=\frac{\left(y_{1} / x_{1}\right)\left(y_{1} / x_{11}\right)}{\left(y_{0} / x_{0}\right)\left(y_{0} / x_{00}\right)}=\frac{x_{11}}{x_{00}} .
\end{gathered}
$$

Using these models and the Fare et al. [42] approach it is thus possible to provide four efficiency/productivity indices for each firm and a technical progress measure over time [47]. These are as follows: (i) technical efficiency change (E) (i.e., relative to a constant returns-to-scale technology); (ii) technological change $(P)$; (iii) pure technical efficiency change (PT) (i.e., relative to a variable returns-to-scale technology); (iv) scale efficiency change (S); and (v) total factor productivity $(M)$ change. Recalling that $M$ indicates the degree of productivity change, then if $M>1$ then productivity gains occur, whilst if $M<1$, productivity losses occur. Regarding changes in efficiency, technical efficiency increases (decreases) if and only if $E$ is greater (less) than one. The technological change index interpretation is that technical progress (regress) has occurred if $P$ is greater (less) than one [32].

An assessment can also be made of the major sources of productivity gains/losses by comparing the $E$ and $P$ values. If $E>P$, then productivity gains are largely the result of improvements in efficiency, whereas if $E<P$, productivity gains are primarily the result of technological progress $[32,48]$. In addition, an indication of the major source of efficiency change can be obtained by recalling that overall technical efficiency is the product of pure technical efficiency and scale efficiency, such that $E=\mathrm{PT} \times S$. Thus, if PT $>S$, then the major source of efficiency change (both increase and decrease) is an improvement in pure technical efficiency, whereas if $\mathrm{PT}<S$, the major source of efficiency is an improvement in scale efficiency [32].

There are many different researches that have applied MPI to evaluate cross-period efficiency. Worthington [49] 
employed MPI productivity growth decomposed into technical efficiency change and technological change for two hundred and sixty-nine Australian credit unions. Odeck [32] used MPI to analyze the efficiency and productivity growth of Norwegian Motor Vehicle Inspection Agencies for the period 1989-91. Zheng et al. [50] investigated the productivity performance of SOEs using data envelopment analysis and a MPI based on a sample of about 600 state enterprises from 1980 to 1994. Chen and Ali [51] proposed a new approach that reveals patterns of productivity change and presents a new interpretation along with the managerial implication of each Malmquist component and also identifies the strategy shifts of individual $D M U_{k}$ based upon isoquant changes. Pastor and Lovell [52] proposed a global MPI that gives a single productivity change measure. Zelenyuk [53] found a theoretically justified method of aggregating MPI over individual decision making units into a group MPI. Wei et al. [54] used MPI decomposition and investigated the energy efficiency of China's iron and steel sector during the period 1994-2003. Liu and Wu [55] used MPI to analyze the total factor productivity change in China's logistics industry with panel data of logistics listed corporation from 1999 to 2006. Liu and Wang [56] employed data envelopment analysis to measure the MPI of semiconductor packaging and testing firms in Taiwan from 2000 to 2003. Barros [57] estimated changes in total productivity, breaking this down into technically efficient change and technological change, using data envelopment analysis applied to the hydroelectric energy generating plants of EDP, the Portugal Electricity Company. Rezitis [58] investigated the effect of acquisition activity on the efficiency and total factor productivity of Greek banks.

\section{Research Design}

In this section we propose our research framework and describe our variable measurement and sample selection.

3.1. Research Framework. This research measures the performance of LED companies in Taiwan for the period 20032009 (see Figure 2). The model outputs are two well-known overall performance measures: net operating revenue and gross profit determine the relative efficiencies of the first tier industries in our sample using the four inputs, total assets, number of employees, operating expense, operating expense, and operating cost, to generate the two outputs. This allows the identification of efficiency differentiators, which proves very useful for inefficient industries because it allows them to spot their weaknesses and improve performance. This study applies the DEA approach to reveal the extent to which inputs can be augmented while maintaining the same level of outputs. We employed window analysis to determine the long-term effectiveness in productivity. Finally, we adopted MPI to identify the major source of productivity growth and separate the catching effect from efficiency changes over time due to technological advancements. This study uses a DEA model to establish a foundation for measuring the efficiency of ten LED companies in Taiwan.

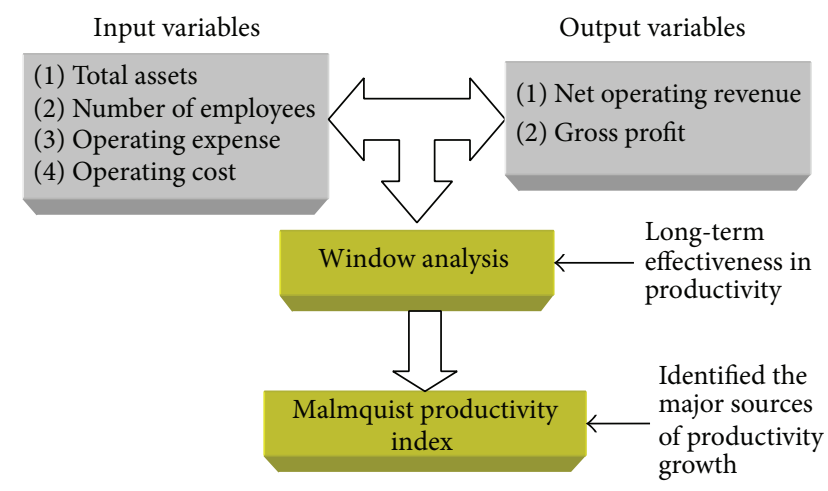

FIGURE 2: Research framework.

3.2. Variable Measurement and Sample Selection. Frontier models require the identification of inputs (resources) and outputs (transformation of resources). Several criteria can be used in their selection. The first empirical criterion is availability. The literature survey is a way of ensuring the research validity and thus represents another criterion to be taken into account. The research samples are ten LED companies in Taiwan. The upstream and midstream LED companies are Tekcore, Tyntek, Epistar, and Forepi. The downstream LED companies are Everlight, Ledtech electronics, Bright LED electronics, Unity Opto Technology, Para light electronics, and Harvatec. This research period $D M U_{s}$ is from 2003 to 2009. We used four input variables and two output variables. The input variables are total assets, number of employees, operating expense, and operating cost. The output variables are net operating revenue and gross profit. The data source is the Taiwan Economic Journal Database Bureau.

\section{Empirical Results}

Our study developed a performance evaluation system for Taiwan LED companies. We conduct the correlation analysis, window analysis, and Malmquist productivity indexes analysis in this section. LED industry products are mainly used in displays, automotive, lighting, building decoration, outdoor advertisement, transportation, and other fields.

Taiwan is the second largest LED manufacturing country in the world in terms of output quantity, just after Japan. The output value of LEDs in Taiwan was USD 1.423 billion for the year 2007 , which took about $21.6 \%$ share of the global output. It is estimated that the figure will rise to USD 1.595 billion in 2008 , representing an annual growth rate of $12.1 \%$. At present, LED manufacturers in Taiwan are focusing on the production and sales of AlGaInP and blue LEDs.

Just like the IT industry, Taiwan plays an important role in the LED industry. The main reason is the complete and specialized vertical disintegration. Taiwan manufacturers are deeply involved in different areas ranging from epitaxy in the upstream, chips in the middle-stream to packaging in the downstream. As opposed to the highly integrated industrial production in other countries, Taiwan's LED industry is more flexible and more capable of providing quality services to fulfill the needs of a variety of customers. 
The LED industry chain in Taiwan is comprised of numerous manufacturers including epitaxy in the upstream, chips in the middle-stream and packaging in the downstream. Currently, there are altogether about 200 manufacturers that form a very much complete structure. In terms of terminal applications, enterprises such as China Electric, Tatung, Forward Electronics, LiteOn, Alliance Optotek, Epistar, I-Chiun, Lustrous, and Wei Min have already engaged in the LED lighting industry and made strides into automobile electronics and monitor applications as well. The whole LED industry supply and demand chain is therefore complete.

The upstream and midstream LED companies in Taiwan include Tekcore, Tyntek, Epistar, and Forepi. Hence, the comprehensive product lines, customer base and patent coverage, have made Taiwan a world class LED manufacturing center. For LED packaging, the downstream LED company in Taiwan has Everlight, Ledtech electronics, Bright LED electronics, Unity Opto Technology, Para light electronics, and Harvatec. In this research, we choose all Taiwanese LED companies as our DMUS.

Ten listed LED companies were selected as the study samples. The upstream and midstream LED companies are Tekcore, Tyntek, Epistar, and Forepi; the downstream LED companies are Everlight, Ledtech electronics, Bright LED electronics, Unity Opto Technology, Para light electronics, and Harvatec. The financial data used in the study were derived from the Taiwan Economic Journal Database. The tools used in data processing and analysis are EXCEL2003 and DEAP 2.1.

4.1. Window Analysis. DEA window analysis can be performed using the Excel Solver via Visual Basic application. Microsoft Company, 2003 Microsoft Company (2003) Excel. Seattle, USA. We assumed constant returns to scale; that is, as all inputs double, all outputs will double. The window analysis enables us to identify the best and the worst industries in a relative sense, as well as the most stable and variable industries in DEA scores. The overall efficiency for each $D M U_{k}$ is calculated using the CCR model [32]. DEA window analysis is also applied. The efficiency scores reported above are from panel data analyses, where the observations for ten LED companies in Taiwan in different years are treated as separate observations, with all measured against each other. This may not be a reasonable assumption because of technological improvements occurring over the 7 year period under analysis. This could make the comparison of units in different years unfair or unrealistic. The above results indicate this expected general tendency for improvements over time. To deal with the problem of unfair comparisons occurring when including all 7 years in the same analysis, we suggest using a window rather than a panel data approach, with a window width of 3 years. This means that observations are only compared to other observations within a 3-year time span.

The scores for an industry in different years within the same window show how the efficiency of an industry changes from one year to another. The column view shows the efficiency for the same year but measured against different

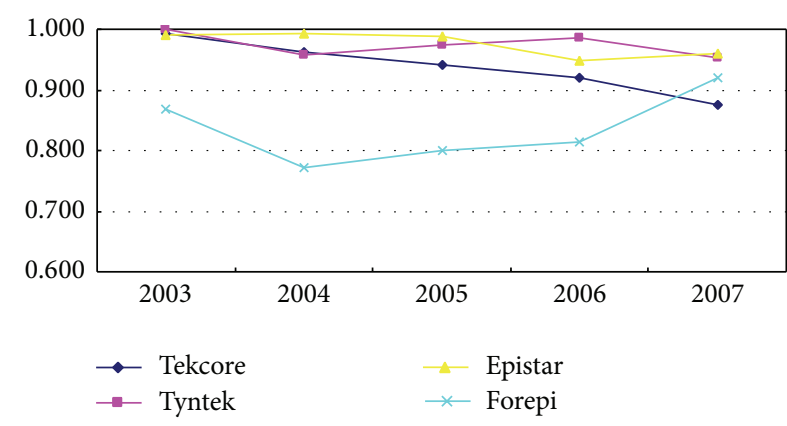

FIGURE 3: Window analysis results of upstream and midstream LED companies.

windows and illustrates the impact of changing the units used to generate the frontier.

We can get the mean, standard division, column range, and total range values from the window analysis result. According to the mean value, we can understand the longterm effectiveness in productivity. The variance in efficiency reflects the fluctuation in efficiency values for each alternative. Column range, $\mathrm{CR}_{l, m}$, can be used to compare the fluctuations of efficiencies among the alternatives. We can use the total range to evaluate the stability of an alternative over different periods. The total range is the difference between the maximum and minimum efficiency values of alternatives in all windows.

The information in Table 1 can be used to compare the performance of different upstream and midstream LED companies as illustrated in Figure 3 . Figure 3 shows the average efficiency score for different LED companies for each window in the analysis.

Observing the average efficiency values, Epistar company has the highest score with a mean of 0.976 , followed by Tyntek and Tekcore. On top of that, Tyntek has the lowest standard division of 0.044 . Regarding the CR value, the best upstream and midstream LED company is Epistar, and the second best is Tekcore. Tyntek also has the best TR value of 0.142 , followed by Epistar and Tekcore.

The information in Table 2 can be used to compare the performance of the different downstream LED companies as illustrated in Figure 4. Figure 4 shows the average efficiency score for the different downstream LED companies for each window in the analysis.

Observing the average efficiency values, Bright LED electronics has the highest score with a mean of 0.997, followed by Everlight and Harvatec. On top of that, Bright LED electronics has the lowest standard division of 0.025 . Regarding the CR value, the best downstream LED company is Bright LED electronics, and the second best is Unity Opto Technology. Bright LED electronics also has the best TR value of 0.025 , followed by Everlight and Para light electronics.

We conducted the DEA Malmquist productivity approach to identify the major source of productivity growth and separate the catching effect from efficiency changes over time due to technological advancements. The DEA Malmquist productivity approach shows that in-depth 
TABLE 1: 2003 2009 total efficiency-window analysis of upstream and midstream LED companies.

\begin{tabular}{|c|c|c|c|c|c|c|c|c|c|c|c|}
\hline & 2003 & 2004 & 2005 & 2006 & 2007 & 2008 & 2009 & & Mean efficiency & Standard division & Total range \\
\hline \multirow{5}{*}{ Tekcore } & 0.983 & 1.000 & 0.995 & & & & & 0.993 & 0.938 & 0.074 & 0.247 \\
\hline & & 1.000 & 0.968 & 0.922 & & & & 0.963 & & & \\
\hline & & & 1.000 & 0.979 & 0.841 & & & 0.940 & & & \\
\hline & & & & 1.000 & 0.855 & 0.903 & & 0.919 & & & \\
\hline & & & & & 0.918 & 0.953 & 0.753 & 0.875 & & & \\
\hline \multirow[t]{3}{*}{$\mathrm{CR}_{1, m}$} & $\mathrm{x}$ & 0.000 & 0.032 & 0.078 & 0.077 & 0.050 & $\mathrm{x}$ & $\mathrm{CR}_{1}$ & 0.078 & & \\
\hline & 1.000 & 1.000 & 1.000 & & & & & 1.000 & 0.974 & 0.044 & 0.142 \\
\hline & & 0.952 & 0.923 & 1.000 & & & & 0.958 & & & \\
\hline \multirow[t]{3}{*}{ Tyntek } & & & 0.920 & 1.000 & 1.000 & & & 0.973 & & & \\
\hline & & & & 1.000 & 1.000 & 0.955 & & 0.985 & & & \\
\hline & & & & & 1.000 & 1.000 & 0.858 & 0.953 & & & \\
\hline \multirow[t]{3}{*}{$\mathrm{CR}_{2, m}$} & $\mathrm{x}$ & 0.048 & 0.080 & 0.000 & 0.000 & 0.045 & $\mathrm{x}$ & $\mathrm{CR}_{2}$ & 0.080 & & \\
\hline & 1.000 & 1.000 & 0.969 & & & & & 0.990 & 0.976 & 0.048 & 0.157 \\
\hline & & 1.000 & 0.980 & 1.000 & & & & 0.993 & & & \\
\hline \multirow[t]{3}{*}{ Epistar } & & & 0.963 & 1.000 & 1.000 & & & 0.988 & & & \\
\hline & & & & 1.000 & 1.000 & 0.843 & & 0.948 & & & \\
\hline & & & & & 1.000 & 0.880 & 1.000 & 0.960 & & & \\
\hline \multirow[t]{3}{*}{$\mathrm{CR}_{3, m}$} & $\mathrm{x}$ & 0.000 & 0.017 & 0.000 & 0.000 & 0.037 & $\mathrm{x}$ & $\mathrm{CR}_{3}$ & 0.037 & & \\
\hline & 0.987 & 0.923 & 0.692 & & & & & 0.867 & 0.835 & 0.111 & 0.317 \\
\hline & & 0.940 & 0.704 & 0.671 & & & & 0.772 & & & \\
\hline \multirow[t]{3}{*}{ Forepi } & & & 0.805 & 0.710 & 0.884 & & & 0.800 & & & \\
\hline & & & & 0.717 & 0.887 & 0.839 & & 0.814 & & & \\
\hline & & & & & 0.940 & 0.854 & 0.967 & 0.920 & & & \\
\hline $\mathrm{CR}_{4, m}$ & $\mathrm{x}$ & 0.017 & 0.113 & 0.046 & 0.056 & 0.015 & $\mathrm{x}$ & $\mathrm{CR}_{4}$ & 0.113 & & \\
\hline
\end{tabular}

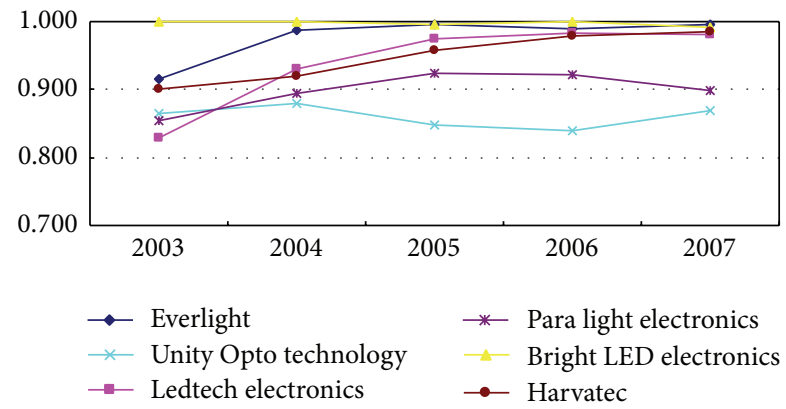

FIGURE 4: Window analysis results of downstream LED companies.

information can be obtained by analyzing each individual MPI component [59, 60]. Such analyses are sometimes very critical in comprehensively capturing an industry's performance. Through an analysis of the MPI components we reveal the managerial implications of each component. The results from these analyses are then further examined using the MPI approach and its decomposition. Hence we saw separation in the catching up effect from the frontier shift, and we clearly observed how the frontier shift is the determinant for productivity growth, with the catching up effect being neutral or negative depending on the assumptions used. From the MPI results, we know that industries not only enhance their managerial skills but also increase and improve innovative performance and upgrade technology $[32,61]$.
4.2. Malmquist Productivity Indexes Analysis. Malmquist indices for the period 2003 to 2009 are presented below for the sample of ten LED companies in Taiwan. Using this information two primary issues are addressed in our Malmquist productivity growth indices computation over the sample period. The first is the productivity change measurement over the period. The second is to decompose changes in productivity into what are generally referred to as a "catching-up" effect (efficiency change) and a "frontier shift" effect (technological change). In turn, the "catchingup" effect is further decomposed to identify the main sources of improvement, through either enhancements in technical efficiency or increases in scale efficiency $[49,50]$.

DEA allows for the estimation of total productivity change in the form of the Malmquist index. The results are presented in Tables 3-6, with the Malmquist index, denoted total productivity change, broken down into technically efficient change (the diffusion or catch-up component), and technologically efficient change (the innovation or frontiershift component). Moreover, we break down technically efficient change into pure efficient change and scale-efficient change.

In Table 3 we can see that the total productivity change score (the MPI presented in column 5) for upstream and midstream LED companies is higher than one for almost all periods, except for 2003-2004 and 2006-2007, showing that a large proportion of the four upstream and midstream LED companies in Taiwan experienced gains in total productivity 
TABLE 2: 2003 2009 total efficiency-window analysis of downstream LED companies.

\begin{tabular}{|c|c|c|c|c|c|c|c|c|c|c|c|}
\hline & 2003 & 2004 & 2005 & 2006 & 2007 & 2008 & 2009 & & Mean efficiency & Standard division & Total range \\
\hline \multirow{5}{*}{ Everlight } & 0.912 & 0.918 & 0.919 & & & & & 0.916 & 0.977 & 0.034 & 0.088 \\
\hline & & 0.977 & 1.000 & & & & & 0.988 & & & \\
\hline & & & 1.000 & 1.000 & 0.990 & & & 0.997 & & & \\
\hline & & & & 1.000 & 1.000 & 0.970 & & 0.990 & & & \\
\hline & & & & & 1.000 & 1.000 & 0.989 & 0.996 & & & \\
\hline $\mathrm{CR}_{1, m}$ & $\mathrm{x}$ & 0.059 & 0.081 & 0.000 & 0.010 & 0.030 & $\mathrm{x}$ & $\mathrm{CR}_{1}$ & 0.081 & & \\
\hline \multirow{5}{*}{ Ledtech electronics } & 0.782 & 0.834 & 0.873 & & & & & 0.830 & 0.939 & 0.065 & 0.218 \\
\hline & & 0.911 & 0.929 & 0.948 & & & & 0.929 & & & \\
\hline & & & 0.955 & 0.969 & 1.000 & & & 0.975 & & & \\
\hline & & & & 0.969 & 1.000 & 0.978 & & 0.982 & & & \\
\hline & & & & & 1.000 & 0.994 & 0.949 & 0.981 & & & \\
\hline $\mathrm{CR}_{2, m}$ & $\mathrm{x}$ & 0.077 & 0.082 & 0.021 & 0.000 & 0.017 & $\mathrm{x}$ & $\mathrm{CR}_{2}$ & 0.082 & & \\
\hline \multirow{5}{*}{ Bright LED electronics } & 1.000 & 1.000 & 1.000 & & & & & 1.000 & 0.997 & 0.007 & 0.025 \\
\hline & & 1.000 & 1.000 & 1.000 & & & & 1.000 & & & \\
\hline & & & 1.000 & 0.989 & 1.000 & & & 0.996 & & & \\
\hline & & & & & 1.000 & 1.000 & & 1.000 & & & \\
\hline & & & & & 1.000 & 0.975 & 1.000 & 0.992 & & & \\
\hline $\mathrm{CR}_{3, m}$ & $\mathrm{x}$ & 0.000 & 0.000 & 0.011 & 0.000 & 0.025 & $\mathrm{x}$ & $\mathrm{CR}_{3}$ & 0.025 & & \\
\hline \multirow{5}{*}{ Unity Opto Technology } & 0.871 & 0.934 & 0.792 & & & & & 0.865 & 0.861 & 0.047 & 0.179 \\
\hline & & 0.971 & 0.858 & 0.813 & & & & 0.881 & & & \\
\hline & & & 0.863 & 0.815 & 0.863 & & & 0.847 & & & \\
\hline & & & & 0.815 & 0.876 & 0.830 & & 0.840 & & & \\
\hline & & & & & 0.876 & 0.846 & 0.887 & 0.870 & & & \\
\hline $\mathrm{CR}_{4, m}$ & $\mathrm{x}$ & 0.037 & 0.072 & 0.002 & 0.013 & 0.016 & $\mathrm{x}$ & $\mathrm{CR}_{4}$ & 0.072 & & \\
\hline \multirow{5}{*}{ Para light electronics } & 0.841 & 0.870 & 0.849 & & & & & 0.853 & 0.898 & 0.031 & 0.099 \\
\hline & & 0.911 & 0.887 & 0.888 & & & & 0.895 & & & \\
\hline & & & 0.932 & 0.928 & 0.910 & & & 0.923 & & & \\
\hline & & & & 0.941 & 0.920 & 0.904 & & 0.921 & & & \\
\hline & & & & & 0.927 & 0.904 & 0.867 & 0.899 & & & \\
\hline $\mathrm{CR}_{5, m}$ & $\mathrm{x}$ & 0.041 & 0.083 & 0.052 & 0.017 & 0.000 & $\mathrm{x}$ & $\mathrm{CR}_{5}$ & 0.083 & & \\
\hline \multirow{5}{*}{ Harvatec } & 1.000 & 0.834 & 0.866 & & & & & 0.900 & 0.948 & 0.050 & 0.166 \\
\hline & & 0.908 & 0.950 & 0.901 & & & & 0.919 & & & \\
\hline & & & 0.968 & 0.945 & 0.962 & & & 0.958 & & & \\
\hline & & & & 0.970 & 0.989 & 0.977 & & 0.979 & & & \\
\hline & & & & & 1.000 & 0.990 & 0.964 & 0.984 & & & \\
\hline $\mathrm{CR}_{6, m}$ & $\mathrm{x}$ & 0.074 & 0.102 & 0.070 & 0.038 & 0.013 & $\mathrm{x}$ & $\mathrm{CR}_{6}$ & 0.102 & & \\
\hline
\end{tabular}

in the six periods considered. The mean MPI is 1.069, which, since it is higher than one, signifies that for the four upstream and midstream LED companies in Taiwan, total productivity decreased from 2003 to 2009.

In Table 4 we can see that the total productivity change score (the MPI presented in column 5) for upstream and midstream LED companies is higher than one for Tekcore, Tyntek, Epistar, and Forepi showing that a large proportion of the three industries experienced gains in total productivity in the period considered. The mean MPI is 1.069, which, since it is higher than one, signifies that for the six high-tech industries, total productivity increased from 2003 to 2009 . The change in the technical efficiency score (column 1) is defined as the diffusion of best-practice technology in the management of the activity and is attributed to investment planning, technical experience, and management and organization in the four upstream and midstream LED companies in Taiwan. For the period under analysis, we can see that it is higher than one for Tekcore, Tyntek, Epistar, and Forepi, signifying that there was an increase in technical efficiency in the period.

The breakdown of the score for the change in technical efficiency into pure technical efficiency change (column 3) and scale-efficiency change (column 4) shows mixed results, with some plants obtaining simultaneous gains in both areas and others obtaining gains in one, but losses in the other. The improvement in pure technical efficiency, which signifies an improvement in managerial skills, shows that there was investment in organizational factors associated with the management of plants, such as a better balance between 
TABLE 3: Malmquist productivity index summary of annual means of upstream and midstream LED companies.

\begin{tabular}{lccccc}
\hline Year & Effch $^{1}$ & Techch & Pech & Sech & Tfpch (MPI) \\
\hline 2003 2004 & 1.021 & 0.978 & 1.000 & 1.021 & 0.982 \\
$2004 \sim 2005$ & 0.982 & 1.206 & 1.000 & 1.028 & 1.185 \\
$2005 \sim 2006$ & 0.955 & 1.086 & 0.929 & 1.009 & 1.038 \\
$2006 \sim 2007$ & 1.047 & 0.890 & 1.038 & 0.995 & 1.995 \\
$2007 \sim 2008$ & 1.021 & 1.231 & 1.027 & 1.005 & 1.007 \\
$2008 \sim 2009$ & 1.015 & 1.021 & 1.010 & & \\
\hline Mean & 1.007 & 1.062 & & &
\end{tabular}

TABLE 4: Malmquist productivity index summary of upstream and midstream LED companies means.

\begin{tabular}{llllll}
\hline & Effch & Techch & Pech & Sech & Tfpch (MPI) \\
\hline Tekcore & 1.027 & 1.094 & 1.000 & 1.027 & 1.000 \\
Tyntek & 1.000 & 1.058 & 1.000 & 1.000 & 1.058 \\
Epistar & 1.000 & 1.064 & 1.000 & 1.000 & 1.064 \\
Forepi & 1.000 & 1.032 & 1.000 & 1.007 & 1.069 \\
\hline Mean & 1.007 & 1.062 & 1.000 & & \\
\hline
\end{tabular}

inputs and outputs, best-practice initiatives, more accurate reporting, an improvement in quality, and so on. The scale efficiency, which is the consequence of size, increases in the period for many plants, due to the increase in capacity utilization [57]. It is important to note that the mean amount of technical efficiency improvement is 1.007 (mean), the mean value of pure technical efficiency change is 1.000 and the mean value of scale-efficiency change is 1.007 . This is a relatively high improvement in efficiency.

Technological change (column 2) is the consequence of innovation, that is, the adoption of new technologies, by bestpractice hydroelectric plants [57]. Its mean value is 1.062 and this index is higher than one for four upstream and midstream LED companies in Taiwan. The value of technological change is larger than one for Tekcore, Tyntek, Epistar, and Forepi. This indicates that innovation improved in the period for Tekcore, Tyntek, Epistar, and Forepi, meaning that there was investment in new technologies (methodologies, procedures, and techniques) and in the commensurate skills upgrades related to this.

In Table 5 we can see that the total productivity change score (the MPI presented in column 5) for downstream LED companies is higher than one for almost all periods, except for 2005-2006, showing that a large proportion of the six downstream LED companies in Taiwan experienced gains in total productivity in the six periods considered. The mean MPI is 1.031, which, since it is higher than one, signifies that for the four upstream and midstream LED companies in Taiwan, total productivity decreased from 2003 to 2009.

In Table 6, we can see that the total productivity change score (the MPI presented in column 5) for downstream LED companies is higher than one for all downstream LED companies showing that a large proportion of the downstream LED companies experienced gains in total productivity in the period considered. The mean MPI is 1.031, which, since it is higher than one, signifies that for the downstream LED companies, total productivity increased from 2003 to 2009. The change in the technical efficiency score (column 1) is defined as the diffusion of best-practice technology in the management of the activity and is attributed to investment planning, technical experience, and management and organization in the downstream LED companies in Taiwan. For the period under analysis, we can see that it is higher than one signifying that there was an increase in technical efficiency in the period.

The score breakdown for the change in technical efficiency into pure technical efficiency change (column 3) and scale-efficiency change (column 4) shows mixed results, with some plants obtaining simultaneous gains in both areas and others obtaining gains in one, but losses in the other. The improvement in pure technical efficiency, which signifies an improvement in managerial skills, shows that there was investment in organizational factors associated with plant management, such as a better balance between inputs and outputs, best-practice initiatives, more accurate reporting, an improvement in quality, and so on. The scale efficiency, which is the consequence of size, increases in the period for many plants, due to the increase in capacity utilization [57]. It is important to note that the mean amount of technical efficiency improvement is 0.986 (mean), the mean value of pure technical efficiency change is 0.999 and the mean value of scale-efficiency change is 0.987 . This is a relatively low improvement in efficiency.

Technological change (column 2) is the consequence of innovation, that is, the adoption of new technologies, by best-practice hydroelectric plants [57]. Its mean value is 1.045 , and this index is higher than one for six downstream LED companies in Taiwan. The technological change value is larger than one for six downstream LED companies. This indicates that innovation improved in the period for 
TABLE 5: Malmquist productivity index summary of annual means of downstream LED companies.

\begin{tabular}{|c|c|c|c|c|c|}
\hline Year & Effch & Techch & Pech & Sech & Tfpch (MPI) \\
\hline 2003 2004 & 1.002 & 1.006 & 0.996 & 1.005 & 1.008 \\
\hline 2004 2005 & 0.987 & 1.144 & 0.993 & 0.994 & 1.129 \\
\hline $2005 \sim 2006$ & 0.983 & 0.997 & 0.986 & 0.997 & 0.980 \\
\hline $2006 \sim 2007$ & 1.009 & 1.012 & 1.012 & 0.997 & 1.020 \\
\hline 2007 2008 & 1.009 & 1.015 & 1.014 & 0.995 & 1.024 \\
\hline 2008 2009 & 0.931 & 1.107 & 0.993 & 0.938 & 1.031 \\
\hline Mean & 0.986 & 1.045 & 0.999 & 0.987 & 1.031 \\
\hline
\end{tabular}

TABLE 6: Malmquist productivity index summary of annual means of downstream LED companies.

\begin{tabular}{|c|c|c|c|c|c|}
\hline & Effch & Techch & Pech & Sech & Tfpch (MPI) \\
\hline Everlight & 0.986 & 1.062 & 1.000 & 0.986 & 1.046 \\
\hline Ledtech electronics & 0.960 & 1.049 & 1.000 & 0.960 & 1.007 \\
\hline Bright LED electronics & 1.000 & 1.040 & 1.000 & 1.000 & 1.040 \\
\hline Unity Opto Technology & 0.987 & 1.023 & 0.994 & 0.993 & 1.010 \\
\hline Para light electronics & 0.986 & 1.034 & 1.000 & 0.986 & 1.020 \\
\hline Harvatec & 1.000 & 1.063 & 1.000 & 1.000 & 1.063 \\
\hline Mean & 0.986 & 1.045 & 0.999 & 0.987 & 1.031 \\
\hline
\end{tabular}

six downstream LED companies, meaning that there was investment in new technologies (methodologies, procedures, and techniques) and in the commensurate skills upgrades related to this.

\section{Conclusions and Remarks}

Performance is "accomplishment" and "efficiency." Accomplishment means the exterior efficiency of the business; efficiency means the level of inner business circulation [61]. Evaluating performance scientifically and reasonably and establishing a performance evaluation model have become the core contents of performance evaluation. Performance evaluation is an important approach for enterprises to give incentives and restraint to their operators. It is also an important channel for enterprise stakeholders to obtain performance information $[62,63]$.

This study analyzed the operating efficiency of ten LED companies in Taiwan for the period 2003-2009. This study indicated how the DEA approach is used to identify individual years that are less efficient than other comparable years in terms of output factors relative to the input factors [60]. The most recent style for measuring efficiency is data envelopment analysis, which is a linear program approach based on this concept. Data envelopment analysis measures the efficiency of decision making units by performing linear programing for each in comparison to other units. Accordingly the decision making units that lie on the frontier curve are efficient in choosing the optimal mixture of inputs to achieve the aimed level of outputs. We used data envelopment analysis to advise inefficient units by initiating certain changes in inputs and/or outputs to improve their efficiencies [33, 64].

This paper applied DEA windows analysis to determine the efficiency of ten LED companies in Taiwan for the period 2003-2009 over time. This approach is advocated in favor of the commonly used cross-sectional data analysis. We have shown how this approach enables calculating efficiency scores even for a small number of different units with a fairly large number of variables. We can use DEA window analysis to evaluate the efficiency of different LED companies over a long term and obtain a best industry that is relatively more efficient for performance. The issue of how same period efficiencies should be defined in a window analysis was discussed and illustrated empirically. In a situation in which industries have made recent investments to achieve beneficial results in the future, or simply just as a result of random effects, the traditional cross-sectional approach may produce misleading results. This study concludes that the efficiency of the different industries can fluctuate over time to different extents.

We conducted the DEA Malmquist productivity approach to identify the major source of productivity growth and separate the catching effect from efficiency changes over time due to technological advancements. The DEA Malmquist productivity approach shows that in-depth information can be obtained by analyzing each individual MPI component. Such analyses are sometimes very critical in comprehensively capturing an industry's performance. Through MPI components analysis we revealed the managerial implications of each component. The results from these analyses were then further examined using the MPI approach and its decomposition. Hence we saw the separation of the catching up effect from the frontier shift, and we clearly observed how the frontier shift is the determinant for productivity growth, with the catching up effect being neutral or negative depending on the assumptions used. From the MPI results we know that industries not only enhance their managerial skills but also increase and improve innovative performance and upgrade technology. 
The Taiwanese LED supply-chain has already experienced several rounds of M\&A and alliance in the last few years, especially for Epistar. The recent trend for Taiwan LED makers is to move toward downstream, that is, packaging, modules and lighting, to increase their revenue/profit, as well as building their relationships with channels to secure their orders. We view the virtual alliance via vertical integration as a positive for Taiwanese LED makers, especially to capture the growing lighting demand.

From the model results we know that industries not only enhance their managerial skills but also increase and improve innovative performance and upgrade technology level.

Better manufacturing ability allows more accurate resource capacity prediction and competing resource requirements provides more accurate production lead time forecasting. This ability comes from the acuity gained through improved communication, scanning, and analysis. Greater responsiveness provides flexibility in reacting to schedule variations and changes. Competing in the marketplace on a cost efficiency basis requires striving for low cost production. In order to keep manufacturing costs competitive, managers must address materials, labor, overhead and other costs. Inventories have long been the focus of cost reduction in factories and are one of the justifications for the JIT system. Therefore, inventory and inventory-related items, such as improving vendor quality and reducing purchased material waste, are considered cost capability indicators. Realizing low inventory levels, decreasing labor costs, and reducing machine time are all positive factors in the cost efficiency construct.

Manufacturing capability is considered an important element in a firm's endeavor to improve firm performance. Manufacturing capability management strategies have reduced inventory and manufacturing cycle times, with more complete, on-time shipments of better quality products. Enterprises should focus on reducing costs and must also pay more attention to building agility and flexibility into their manufacturing processes, seeking better market differentiation. Cost reductions remain the focus of all enterprises and many still struggle with data collection and cultural issues. Manufacturing capability includes five aspects, reducing manufacturing costs, shrinking manufacturing cycle time, improving schedule compliance, and satisfying the demand for more complete and on-time shipments.

Innovation shows up in the quality and quantity of ideas and the efficiency and effectiveness of implementing those ideas. The second face of $\mathrm{R} \& \mathrm{D}$ is called the absorptive capacity. It is considered crucial, particularly for assessing the effective contribution of spillovers from others. Defined as a set of knowledge and competencies, a firm's knowledge base remains a preliminary condition in the assimilation of spillovers from R\&D efforts and the outside environment. R\&D activity does not only stimulate innovation, it also enhances the firms' ability to assimilate outside knowledge.

Successful human resource capability management is important for the high tech industry. Human resource performance management is a huge priority for competitive organizations. That is where superior software solutions come in. By automating much of the human resource performance management process and adding much-needed knowledge and information access to the equation, such solutions can help make these HR initiatives a source of success. Valued human resource development improves professional skills and capabilities and also solves the problem of measuring the human resources effect on an organization. We think that HRM as an instrument designed to enhance the labor extraction process and thus improve firm performance.

Our work provides a good method to evaluate LED companies, but also establishes the foundation to study performance evaluation method for LED companies more deeply. In future work we will promote the performance evaluation model and put forward a more reasonable criteria weight model to improve evaluation efficiency and veracity for LED companies. There are two extensions to this study that can be undertaken. First, although the input side of the DEA model considered all relevant input dimensions in our industry, the output side bears reexamination. Our study only considered two industry performance measures (namely, number of patents and annual sales) due to certain limitations in the sample size associated with DEA implementation. Future studies should consider a more extensive set of business performance measures. Of particular interest would be a DEA model incorporating market-oriented measures such as market share and sales growth. Second, in evaluating the relative efficiency scores using DEA, we did not restrict any input or output weights. This may affect the results if certain input or output measures are more important than others. In future research it may be interesting to identify such weights to reflect relative importance and integrate them into the analysis. This would provide more robust results and conclusions.

\section{Conflict of Interests}

The author declares that there is no conflict of interests regarding the publication of this paper.

\section{Acknowledgments}

This paper is supported by a Grant from the National Science Council (NSC 102-2410-H-032 -081 -SSS) in Taiwan for the work from which this paper derived is gratefully acknowledged.

\section{References}

[1] J. C. Paradi and C. Schaffnit, "Commercial branch performance evaluation and results communication in a Canadian banka DEA application," European Journal of Operational Research, vol. 156, no. 3, pp. 719-735, 2004.

[2] D. Wu, Z. Yang, and L. Liang, "Efficiency analysis of crossregion bank branches using fuzzy data envelopment analysis," Applied Mathematics and Computation, vol. 181, no. 1, pp. 271281, 2006.

[3] S. Chalasani and J. Sounderpandian, "Performance benchmarks and cost sharing models for B2B supply chain information systems," Benchmarking, vol. 11, no. 5, pp. 447-464, 2004. 
[4] K. L. H. Wynn-Williams, "Performance assessment and benchmarking in the public sector: an example from New Zealand," Benchmarking, vol. 12, no. 5, pp. 482-492, 2005.

[5] R. Gleich, J. Motwani, and A. Wald, "Process benchmarking: a new tool to improve the performance of overhead areas," Benchmarking, vol. 15, no. 3, pp. 242-256, 2008.

[6] A. S. Maiga and F. A. Jacobs, "The association between benchmarking and organizational performance: an empirical investigation," Managerial Finance, vol. 30, no. 8, pp. 13-33, 2004.

[7] C. R. Wu, C. T. Lin, and P. H. Tsai, "Evaluating business performance of wealth management banks," European Journal of Operational Research, vol. 207, no. 2, pp. 971-979, 2010.

[8] A. Mukherjee, P. Nath, and M. N. Pal, "Performance benchmarking and strategic homogeneity of Indian banks," The International Journal of Bank Marketing, vol. 20, no. 2-3, pp. 122-139, 2002.

[9] K. S. Chin, K. F. Pun, C. S. Lau, and H. Lau, "Performance improvement of international roaming service," Benchmarking, vol. 8, no. 2, pp. 120-131, 2001.

[10] A. H. Himes, "Performance indicator importance in MPA management using a multi-criteria approach," Coastal Management, vol. 35, no. 5, pp. 601-618, 2007.

[11] K. Jones and Y. Kaluarachchi, "Performance measurement and benchmarking of a major innovation programme," Benchmarking, vol. 15, no. 2, pp. 124-136, 2008.

[12] S. Welch and R. Mann, "The development of a benchmarking and performance improvement resource," Benchmarking, vol. 8, no. 5, pp. 431-452, 2001.

[13] D. Wainwright, G. Green, E. Mitchell, and D. Yarrow, "Towards a framework for benchmarking ICT practice, competence and performance in small firms," Performance Measurement and Metrics, vol. 6, no. 1, pp. 39-52, 2005.

[14] A. Robson and V. B. Prabhu, "What can we learn from, "leading" service practitioners about business excellence," Managing Service Quality, vol. 11, no. 4, pp. 249-261, 2001.

[15] K. S. Park, "Duality, efficiency computations and interpretations in imprecise DEA," European Journal of Operational Research, vol. 200, no. 1, pp. 289-296, 2010.

[16] P. J. Korhonen, M. Soleimani-damaneh, and J. Wallenius, "Ratio-based RTS determination in weight-restricted DEA models," European Journal of Operational Research, vol. 215, no. 2, pp. 431-438, 2011.

[17] H. Z. Rezai and A. Davoodi, "Some remarks on the two-level DEA model," Applied Mathematics Letters, vol. 24, no. 6, pp. 969-974, 2011.

[18] N. Ramón, J. L. Ruiz, and I. Sirvent, "A multiplier bound approach to assess relative efficiency in DEA without slacks," European Journal of Operational Research, vol. 203, no. 1, pp. 261-269, 2010.

[19] J. C. Paradi, S. Rouatt, and H. Zhu, "Two-stage evaluation of bank branch efficiency using data envelopment analysis," Omega, vol. 39, no. 1, pp. 99-109, 2011.

[20] T. Sueyoshi and M. Goto, "DEA approach for unified efficiency measurement: assessment of Japanese fossil fuel power generation," Energy Economics, vol. 33, no. 2, pp. 292-303, 2011.

[21] N. K. Avkiran and T. Rowlands, "How to better identify the true managerial performance: state of the art using DEA," Omega, vol. 36, no. 2, pp. 317-324, 2008.

[22] S. K. Lee, G. Mogi, Z. Li et al., "Measuring the relative efficiency of hydrogen energy technologies for implementing the hydrogen economy: an integrated fuzzy AHP/DEA approach," International Journal of Hydrogen Energy, vol. 36, no. 20, pp. 12655-12663, 2011.

[23] Y. M. Wang and K. S. Chin, "Some alternative DEA models for two-stage process," Expert Systems with Applications, vol. 37, no. 12, pp. 8799-8808, 2010.

[24] S. C. Kumbhakar and C. A. K. Lovell, Stochastic Frontier Analysis, Cambridge University Press, Cambridge, UK, 2000.

[25] J. Du, L. Liang, Y. Chen, and G. Bi, "DEA-based production planning," Omega, vol. 38, no. 1-2, pp. 105-112, 2010.

[26] K. A. Froot and P. D. Klemperer, "Exchange rate pass-through when market share matter," The American Economic Review, vol. 79, no. 4, pp. 637-654, 1989.

[27] F. H. Lotfi, A. A. Noora, G. R. Jahanshahloo, and M. Reshadi, "One DEA ranking method based on applying aggregate units," Expert Systems with Applications, vol. 38, no. 10, pp. 1346813471, 2011.

[28] H. C. Hsiao, H. Chang, A. M. Cianci, and L. H. Huang, "First financial restructuring and operating efficiency: evidence from Taiwanese commercial banks," Journal of Banking and Finance, vol. 34, no. 7, pp. 1461-1471, 2010.

[29] P. T. Chang and J. H. Lee, "A fuzzy DEA and knapsack formulation integrated model for project selection," Computers \& Operations Research, vol. 39, no. 1, pp. 112-125, 2012.

[30] J. H. Dulá, "A computational study of DEA with massive data sets," Computers \& Operations Research, vol. 35, no. 4, pp. 11911203, 2008.

[31] F. Hernández-Sancho, M. Molinos-Senante, and R. SalaGarrido, "Energy efficiency in Spanish wastewater treatment plants: a non-radial DEA approach," Science of the Total Environment, vol. 409, no. 14, pp. 2693-2699, 2011.

[32] J. Odeck, "Assessing the relative efficiency and productivity growth of vehicle inspection services: an application of DEA and Malmquist indices," European Journal of Operational Research, vol. 126, no. 3, pp. 501-514, 2000.

[33] A. Charnes, W. W. Cooper, and E. Rhodes, "Measuring the efficiency of decision making units," European Journal of Operational Research, vol. 2, no. 6, pp. 429-444, 1978.

[34] A. J. C. Trappey and T. A. Chiang, "A DEA benchmarking methodology for project planning and management of new product development under decentralized profit-center business model," Advanced Engineering Informatics, vol. 22, no. 4, pp. 438-444, 2008.

[35] H. Tulkens and P. Vanden Eeckaut, "Non-parametric efficiency, progress and regress measures for panel data: methodological aspects," European Journal of Operational Research, vol. 80, no. 3, pp. 474-499, 1995.

[36] B. Y. H. Wong, M. Luque, and J. B. Yang, "Using interactive multiobjective methods to solve DEA problems with value judgements," Computers \& Operations Research, vol. 36, no. 2, pp. 623-636, 2009.

[37] K. Cullinane, D. W. Song, P. Ji, and T. F. Wang, "An application of DEA windows analysis to container port production efficiency," Review of Network Economics, vol. 3, no. 2, pp. 184-206, 2004.

[38] K. Shahooth and A. H. Battall, "Using data envelopment analysis to measure cost efficiency with an application on Islamic banks," Scientific Journal of Administrative Development, vol. 4, pp. 134-156, 2006.

[39] S. C. Chang, C. P. Lin, and M. S. Lou, "A study on the dynamic operational efficiency analysis of Taiwan's TFT-LCD industry," Taiwan Business Performance Journal, vol. 1, no. 1, pp. 27-52, 2007. 
[40] D. W. Caves, L. R. Christensen, and W. E. Diewert, "Multilateral comparisons of output, input, and productivity using superlative index numbers," Economic Journal, vol. 92, no. 365, pp. 7386, 1982.

[41] M. D. Fethi and F. Pasiouras, "Assessing bank efficiency and performance with operational research and artificial intelligence techniques: a survey," European Journal of Operational Research, vol. 204, no. 2, pp. 189-198, 2010.

[42] R. Fare, S. Grosskopf, M. Norris, and Z. Zhang, "Productivity growth, technical progress, and efficiency change in industrialized countries," The American Economic Review, vol. 84, no. 1, pp. 66-83, 1994.

[43] T. T. Lin, C. C. Lee, and T. F. Chiu, "Application of DEA in analyzing a bank's operating performance," Expert Systems with Applications, vol. 36, no. 5, pp. 8883-8891, 2009.

[44] S. M. Estelle, A. L. Johnson, and J. Ruggiero, "Three-stage DEA models for incorporating exogenous inputs," Computers \& Operations Research, vol. 37, no. 6, pp. 1087-1090, 2010.

[45] J. B. Yang, D. L. Xu, and S. Yang, "Integrated efficiency and trade-off analyses using a DEA-oriented interactive minimax reference point approach," Computers \& Operations Research, vol. 39, no. 5, pp. 1062-1073, 2012.

[46] F. H. F. Liu and H. H. Peng, "Ranking of units on the DEA frontier with common weights," Computers \& Operations Research, vol. 35, no. 5, pp. 1624-1637, 2008.

[47] A. S. Kazley and Y. A. Ozcan, "Electronic medical record use and efficiency: a DEA and windows analysis of hospitals," SocioEconomic Planning Sciences, vol. 43, no. 3, pp. 209-216, 2009.

[48] M. L. Bougnol, J. H. Dulá, and P. Rouse, "Interior point methods in DEA to determine non-zero multiplier weights," Computers \& Operations Research, vol. 39, no. 3, pp. 698-708, 2012.

[49] A. C. Worthington, "Malmquist indices of productivity change in Australian financial services," Journal of International Financial Markets, Institutions and Money, vol. 9, no. 3, pp. 303-320, 1999.

[50] J. Zheng, X. Liu, and A. Bigsten, "Efficiency, technical progress, and best practice in Chinese state enterprises (1980-1994)," Journal of Comparative Economics, vol. 31, no. 1, pp. 134-152, 2003.

[51] Y. Chen and A. I. Ali, "DEA Malmquist productivity measure: new insights with an application to computer industry," European Journal of Operational Research, vol. 159, no. 1, pp. 239-249, 2004.

[52] J. T. Pastor and C. A. K. Lovell, "A global Malmquist productivity index," Economics Letters, vol. 88, no. 2, pp. 266-271, 2005.

[53] V. Zelenyuk, "Aggregation of Malmquist productivity indexes," European Journal of Operational Research, vol. 174, no. 2, pp. 1076-1086, 2006.

[54] Y. M. Wei, H. Liao, and Y. Fan, "An empirical analysis of energy efficiency in China's iron and steel sector," Energy, vol. 32, no. 12, pp. 2262-2270, 2007.

[55] Y. Liu and Y. H. Wu, "Empirical analysis on TFP change in Chinese logistics industry: a nonparametric Malmquist index approach," Chinese Business Review, vol. 6, no. 4, pp. 35-40, 2007.

[56] F. H. F. Liu and P. H. Wang, "DEA Malmquist productivity measure: Taiwanese semiconductor companies," International Journal of Production Economics, vol. 112, no. 1, pp. 367-379, 2008.

[57] C. P. Barros, "Efficiency analysis of hydroelectric generating plants: a case study for Portugal," Energy Economics, vol. 30, no. 1, pp. 59-75, 2008.
[58] A. N. Rezitis, "Efficiency and productivity effects of bank mergers: evidence from the Greek banking industry," Economic Modelling, vol. 25, no. 2, pp. 236-254, 2008.

[59] Y. Chen, G. N. Gregoriou, and F. D. Rouah, "Efficiency persistence of bank and thrift CEOs using data envelopment analysis," Computers \& Operations Research, vol. 36, no. 5, pp. 1554-1561, 2009.

[60] R. B. Staub, G. da Silva e Souza, and B. M. Tabak, "Evolution of bank efficiency in Brazil: a DEA approach," European Journal of Operational Research, vol. 202, no. 1, pp. 204-213, 2010.

[61] A. Neely, M. Gregory, and K. Platts, "Performance measurement system design: a literature review and research agenda," International Journal of Operations and Production Management, vol. 15, no. 4, pp. 80-116, 1995.

[62] X. Luo, "Evaluating the profitability and marketability efficiency of large banks: an application of data envelopment analysis," Journal of Business Research, vol. 56, no. 8, pp. 627-635, 2003.

[63] P. J. Korhonen and P. A. Siitari, "Using lexicographic parametric programming for identifying efficient units in DEA," Computers \& Operations Research, vol. 34, no. 7, pp. 2177-2190, 2007.

[64] P. C. Pendharkar, "A hybrid radial basis function and data envelopment analysis neural network for classification," Computers \& Operations Research, vol. 38, no. 1, pp. 256-266, 2011. 


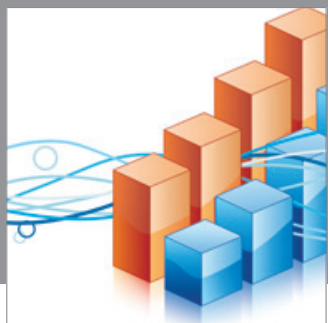

Advances in

Operations Research

mansans

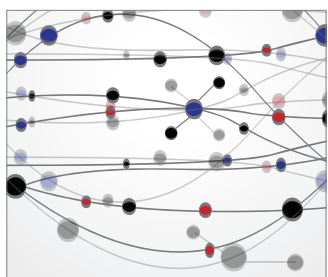

The Scientific World Journal
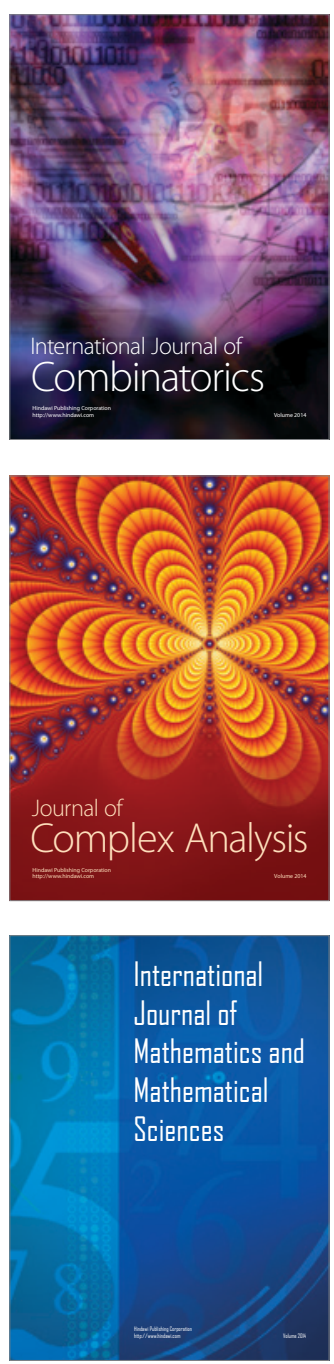
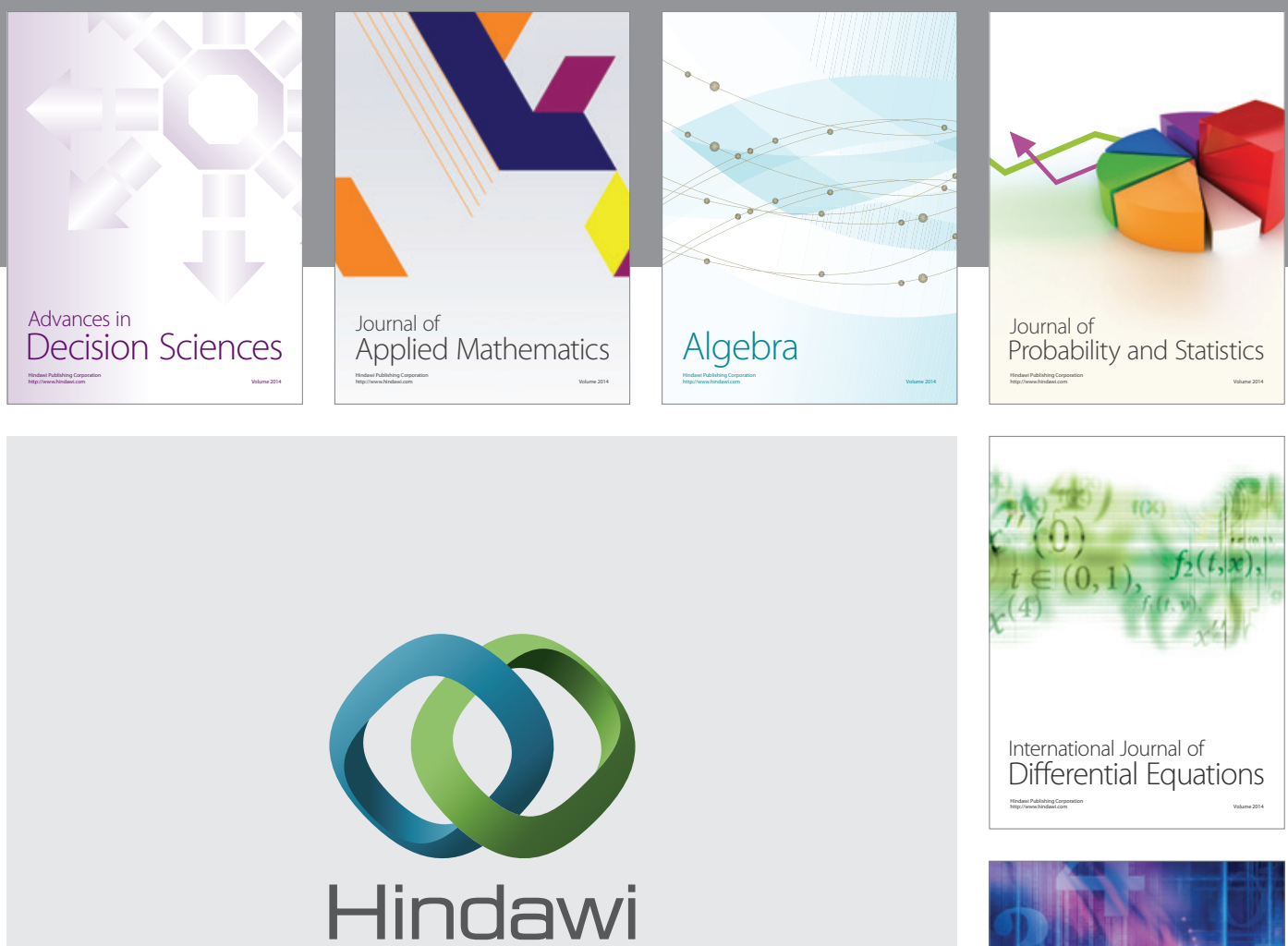

Submit your manuscripts at http://www.hindawi.com
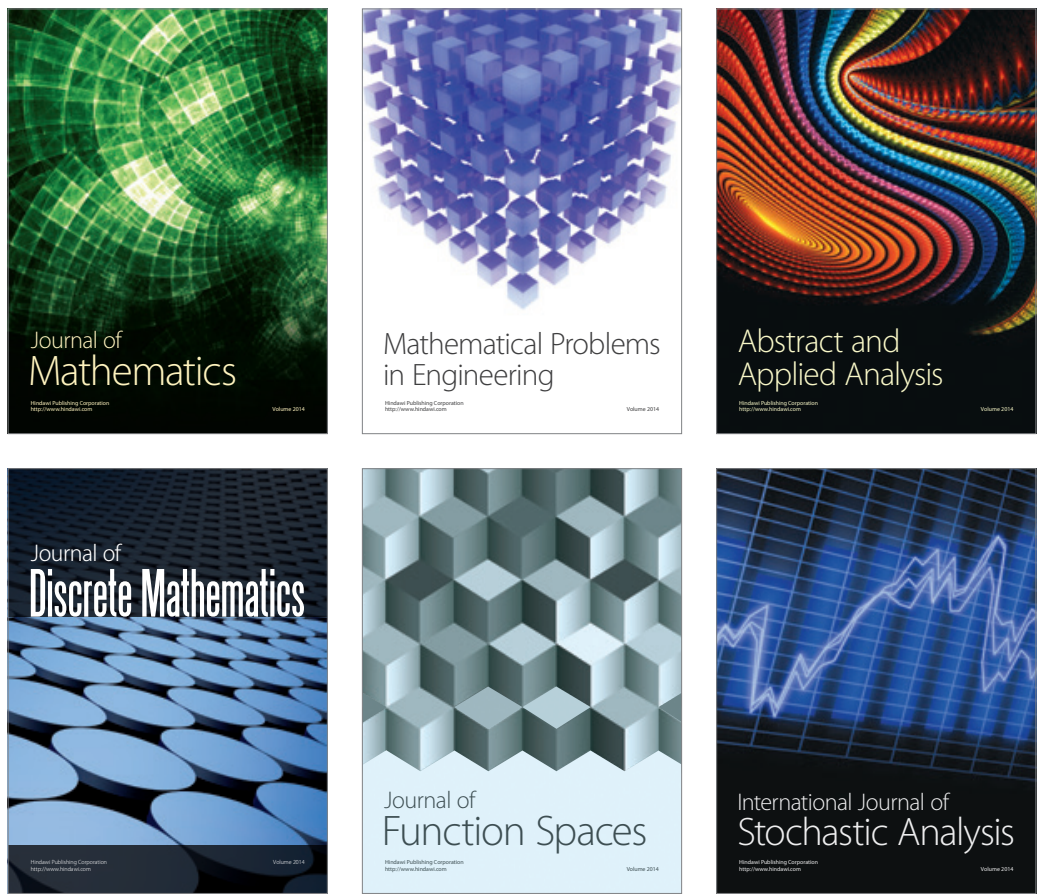

Journal of

Function Spaces

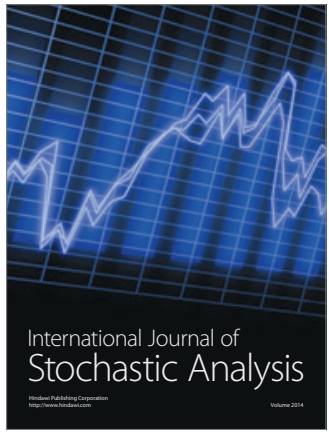

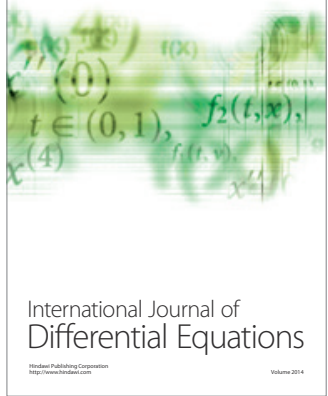
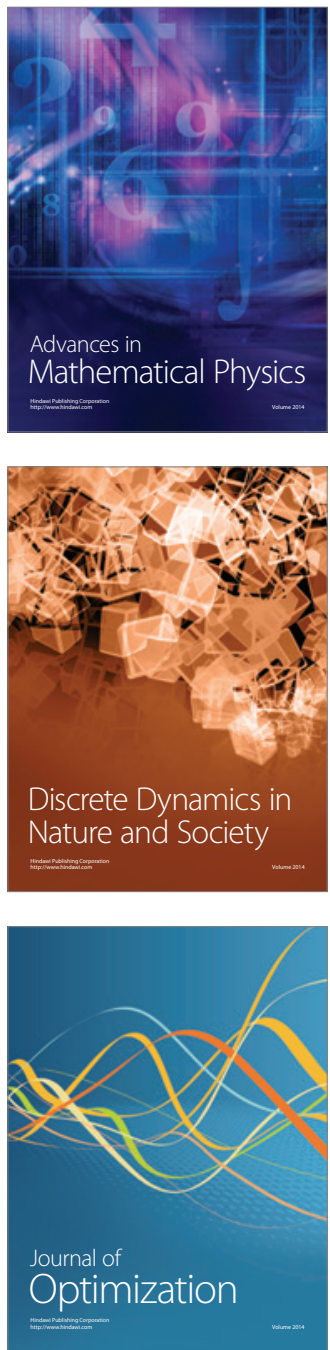